\title{
FÉ MIDIATIZADA? Indagações sobre a abordagem comunicacional da questão religiosa na era das tecnologias digitais em rede
}

\author{
¿FÉ MEDIATIZADA? Indagaciones sobre el enfoque comunicacional \\ sobre la cuestión religiosa en la era de las tecnologías digitales en red
}

\section{MEDIATIZED FAITH? Inquiries about the communicational approach of the religious issue in the era of digital network technologies}

\author{
Fernanda Lima Lopes'
}

Palavras chave:

Religião

Midiatização

Espiritualidade

Fé

Tecnologias

de comunicação digital e em rede

\section{Resumo:}

As novas tecnologias de comunicação digitais e em rede parecem estar onipresentes, invadindo praticamente os mais variados campos da cultura e da sociedade, inclusive os mais tradicionais como o direito, a política, a educação. Diante disso, uma vertente bem recente de estudos de comunicação vem discutindo o conceito de midiatização, procurando enxergar a centralidade da mídia na produção de novas ambiências, novas formas de vida. Neste trabalho, são apresentados alguns desses pontos de vista, mas o principal objetivo é questionar em que medida a noção de midiatização serve de ferramenta teórica a ser aplicada na investigação da relação entre mídia e religião. Incluindo reflexões sobre as particularidades epistemológicas em torno da fé e da espiritualidade, são formuladas questões acerca dos possíveis ajustes e desencaixes da teoria da midiatização como matriz de compreensão dos fenômenos na profundidade e complexidade que tais temas evocam. 


\section{Resumen:}

Las nuevas tecnologías de comunicación digital y en red parecen estar omnipresentes, invadiendo los más variados campos de la cultura y de la sociedad, incluso los más tradicionales como el derecho, la política, la educación. Sobre este facto, una vertiente muy reciente de estudios de comunicación viene discutiendo el concepto de mediatización, buscando ver la centralidad de los medios en la producción de nuevos ambientes, nuevas formas de vida. En este trabajo se presentan algunos de estos puntos de vista, pero el principal objetivo es cuestionar en qué medida la noción de mediatización sirve de herramienta teórica a ser aplicada en la investigación de la relación entre medios y religión. Incluyendo reflexiones sobre las particularidades epistemológicas en torno a la fe y la espiritualidad, se formulan preguntas acerca de los posibles ajustes y desencadenamientos de la teoría de la mediatización como matriz de comprensión de los fenómenos en la profundidad y complejidad que tales temas evocan.

\section{Palabras clave:}

Religión

Mediatización

Espiritualidad

$\mathrm{Fe}$

Tecnologias

de comunicación

digital y en red

\section{Keywords:}

Religion

Mediatization

Spirituality

Faith

Technologies

of digital and networked

communication

\section{Abstract:}

The new technologies of digital and networked communication seem to be ubiquitous, invading every dimension of culture and society, including the most traditional fields such as law, politics, and education. Regarding this, some recent communication studies started discussing the concept of mediatization, considering the centrality of the media in the production of new environments, new ways of life. In this work, some of these points of view are presented, but the main objective is to question to what extent the notion of mediatization serves as a theoretical tool to be applied in the investigation of the relationship between media and religion. Including reflections on the epistemological particularities around faith and spirituality, the article inquires about the possible adjustments and disembodiments of the mediatization theory as a matrix of understanding the phenomena in the depth and complexity that such themes evoke. 


\section{FÉ MIDIATIZADA? \\ Indagações sobre a abordagem comunicacional da questão religiosa na era das tecnologias digitais em rede}

\section{Introdução}

Este artigo propõe lançar um olhar sobre a problemática da midiatização - uma discussão cara aos estudos de comunicação - tendo como horizonte a relativamente recente atenção ao tema religião e mídia demonstrada por estudiosos desse campo, no contexto do aumento da presença da religião nos espaços da visibilidade social constituídos pelos media, seja no espaço nos tradicionais meios de comunicação (impressos, rádio e TV principalmente), seja nos ambientes virtuais da comunicação em rede. O objetivo é estabelecer algumas bases teóricas e levantar alguns questionamentos a fim de que futuras pesquisas, de cunho mais empírico, possam olhar para os fenômenos específicos dessa natureza, considerando tanto sedimentações quanto possíveis tensões epistemológicas pertinentes a uma compreensão mais profunda da complexa realidade em que se observam vivências da fé, de religiosidade, de espiritualidade na sociedade contemporânea.

Os parágrafos que se seguem levantam algumas perspectivas teóricas sobre a questão da midiatização, procurando destacar divergências e aproximações entre autores, demonstrando, assim, que essa concepção está longe de ser um consenso acadêmico. Normalmente associado à questão da centralidade da mídia na atual configuração da sociedade e da cultura - mas não restrito a isso -, o termo que a área se esforça em debater ganha força com os fenômenos comunicacionais do período posterior ao aparecimento da internet. Entre as problemáticas que as propostas em torno da noção de midiatização apresentam não só à comunicação, mas às pesquisas que relacionam comunicação e religião é que elas tendem a pôr em xeque a noção de mediação, importante tanto para os níveis institucionais da comunicação midiática quanto da religião. Antes de passar ao exame mais minucioso das perspectivas teóricas em torno de tais conceitos, é válido fazer alguns esclarecimentos sobre os sentidos de fé, de religião, de espiritualidade que estão sendo considerados neste texto. Em primeiro lugar, reconhece-se que as religiões são traço crucial da(s) cultura(s) e enquanto fenômenos enraizados na história podem - e devem - ser vislumbrados no que respeita aos seus processos de espalhamento geográfico, crescimento, diáspora, institucionalização, perseguição, clandestinidade, resistência, relação com outras esferas da sociedade (por exemplo, com o poder formalmente instituído). Para o antropólogo Cliford Geertz (1978), estudar religião significa duas coisas: analisar o "sistema de significados incorporado nos símbolos que formam a religião propriamente dita" e investigar "o relacionamento desses sistemas aos processos socioestruturais e psicológicos" (GEERTZ, 1978, p.142).

Ainda que os trabalhos acadêmicos se concentrem nesses aspectos, os pesquisadores não podem ignorar que o envolvimento religioso não se esgota na dimensão cultural, porque tampouco se restringe à prática de uma dada sociabilidade ou uma troca simbólica entre sujeitos sociais. Aliás, a existência das religiões se fundamenta num tipo de contato que almeja justamente aquilo que transcende o humano. Por essa razão, mesmo que as pesquisas sobre religião e mídia se localizem no campo da comunicação social e não ousem enveredar por estudos de mística ou ascese (ou 
sequer teologia), não podem abrir mão da compreensão de que a busca pelo transcendente ou demiurgo, a despeito das mais variadas manifestações que a antropologia logrou indicar, é um caráter inerente à identidade religiosa. O teísmo é imprescindível à religião". E a fé associa-se a esse aspecto, mas não se resume a ele, porque há quem viva sua fé independentemente da adesão a uma religião formal, institucional. Já a espiritualidade é algo que pode ser vivida de modo distanciado da adesão religiosa ou mesmo da afirmação de fé em Deus ou em divindades.

Conforme Viktor Frankl (2007), a espiritualidade é um atributo constitutivo do ser humano, assim como os aspectos biológico e psicológico. Tal como aponta o psicanalista austríaco, em diálogo crítico com a Escola de Viena da qual ele mesmo deriva, o inconsciente inclui uma dimensão noológica - isto é, espiritual, de busca por sentido da vida - que não pode ser negligenciada pela "visão atomística" de uma psicanálise que reduza os fenômenos psíquicos a mero resultado de pulsões"I". É nesse sentido tão intrínseco do âmbito espiritual da existência que se postula uma compreensão abrangente sobre o tema da espiritualidade, admitindo-se, portanto, que esta se aplicaria a todo gênero humano, independentemente de sua crença, inclusive ao ateu (cf. COMTE-SPONVILLE, 2007).

Tendo apresentado, ainda que de maneira extremamente breve, as noções gerais de religião, fé e espiritualidade adotadas neste texto, é hora de passar à apresentação do que vem sendo nomeado "midiatização".

\section{Perspectivas epistemológicas sobre midiatização}

Boa parte das pesquisas em comunicação ou estudos de mídia que vêm sendo produzidos no ambiente acadêmico deste século XXI está voltada às chamadas "novas mídias", ao fenômeno da internet, das mídias digitais, da sociedade em rede, da cultura convergente, enfim, do novo cenário comunicacional permeado pelas lógicas do digital, do virtual e da conexão tecnológica em rede. Em diferentes graus e com variados enfoques, trabalhos em torno das transformações do final do século $X X$ e início do XXI indicam que as mudanças não se limitam às tecnologias de comunicação e informação, às empresas de comunicação, aos produtos midiáticos, aos atores sociais envolvidos com o trabalho na mídia, mas abrangem toda sorte de fenômenos sociais e culturais envolvendo tudo isso de maneira integrada e interacional. No bojo de tais reflexões encontram-se as abordagens teóricas que propõem a midiatização - mais do que a mediação - como uma concepção fulcral para o entendimento de tudo isso. Nos parágrafos a seguir, serão apresentadas algumas dessas perspectivas acadêmicas, ao mesmo tempo em que se indagará sobre a possibilidade de incorporá-las aos estudos sobre religião e mídia. Para evitar riscos de apropriações teóricas acríticas e/ou indevidas, espera-se observar eventuais fissuras, incompletudes conceituais e possíveis opacidades da aplicação dessa ferramenta teórica em relação ao terreno citado. Sem perder de vista as particularidades da temática religiosa, incluindo aí as dimensões históricas do universo religioso, serão propostos questionamentos sobre pertinência das teorias da midiatização e serão perscrutados possíveis pontos de contato da reflexão sobre midiatização considerando-se a relação entre a religião e as realidades comunicacionais contemporâneas.

As expressões mediação e midiatização remetem ao termo mídia, que por sua vez, tem origem no termo lati- 
no medium (meio), o qual também deu origem a palavras como intermediário, médium. A etimologia evoca a qualidade de se estar no meio, ou seja, entre uma coisa e outra, donde se desdobram alguns sentidos: o de que medium pode ser entendido como um veículo, um canal, um meio de transporte, um dispositivo material. Mas é válido acrescentar que tal acepção de mediação pode remeter, ainda, a tarefas como tradução, negociação, filtragem.

A problematização e o aprofundamento teórico sobre o conceito de mediação ocuparam importante espaço no debate epistemológico da comunicação, uma área que, segundo Vera França (2001) só irá se organizar como esfera autônoma no mundo acadêmico no século XX. Essa contextualização sobre os estudos acadêmicos de comunicação é relevante, porque sinaliza o quão recente são tais esforços teóricos a se debruçar sobre processos que, a rigor, remontam a eras imemoriais. Há vestígios da comunicação não-verbal por símbolos que remontam à era das cavernas, e a linguagem é ainda anterior a isso.

Embora saibamos que práticas comunicativas existem desde tempos remotos, e mesmo que consideremos que a retórica dos sofistas ou a techné rhethorike de Aristóteles tenham constituído grupos de saberes mais formais sobre o fazer discursivo, só é possível considerar o aparecimento de uma disciplina (ou um campo de saber acadêmico) voltada de modo especial à comunicação a partir do século XX. Os pressupostos metodológicos e científicos advogam que uma área de conhecimento só irá articular sua autonomia em relação a outros campos do saber na medida em que consegue demonstrar que possui um objeto próprio e desenvolver metodologias específicas, o que, no caso da Comunicação, está amplamente associado ao surgimento - e as congruentes análises - do fenômeno da comunicação de massa (FRANÇA, 2001).

O desenvolvimento de teorias nesse campo apresentou, bem como representou, de alguma maneira, a centralidade da mídia para a vida nas sociedades modernas, sinalizando que o crescimento da importância dos meios, dos seus produtos, dos seus discursos, dos seus profissionais, fez frente a outras instâncias da mediação social, como a religião, a família, o sistema de ensino, o executivo, o legislativo, o judiciário etc. $\mathrm{O}$ fato de o jornalismo ter sido denominado de quarto poder não deixa de ser uma indicação nesse sentido.

Sobre as primeiras experiências dos estudos mais específicos em comunicação, é interessante lembrar que a relevância mediadora dos veículos massivos serviu de motor para variadas perspectivas, como as pesquisas americanas da primeira metade do século $\mathrm{XX}$, que ficaram conhecidas como "mass communication research", as quais incluíram investigações sobre o papel social da mídia (teorias funcionalistas), efeitos da comunicação junto ao público (aguIha hipodérmica, teorias dos efeitos), seus modelos e modus operandi (teoria matemática) (ARAÚJO, 2001). Embora com abordagens e vinculações ideológicas radicalmente distintas destes, os trabalhos de pensadores europeus, como os da Escola de Frankfurt, de meados do século passado, também reservaram um lugar de destaque à ação dos meios na sociedade, julgando que esses foram constituídos segundo uma lógica industrial e massiva, e que o crescimento do que eles denominaram "indústria cultural" foi responsável pela decadência da cultura e por outras transformações sociais ligadas à perda de conhecimento erudito e ameaça à capacidade crítica sobre a sociedade. 
Na década de 1980, Martin-Barbero propôs um deslocamento do olhar "dos meios às mediações", procurando, por um lado, se afastar da concepção de "cultura de massa" entendida como "conjunto de meios massivos de comunicação" (2006, p.196) e, por outro lado, dar destaque ao que ele chamou "mediações culturais", enfatizando o âmbito da cultura. Esse trabalho do autor é marcadamente culturalista, além de exibir traços claros de uma influência marxista e de algumas releituras de Marx, como as de Gramsci e de autores dos estudos culturais britânicos. O conceito de hegemonia acompanha a proposta teórica de Barbero acerca de processos políticos, econômicos, sociais e de instituições mediadoras na política, na economia e na sociedade, sobretudo na América Latina. Sujeitos e instituições são analisados sob a ótica das formas de hegemonia na produção, distribuição e consumo dos produtos massificados produzidos pelas mídias. E quanto às mediações, o autor igualmente segue a perspectiva culturalista quando as localiza em três locais de especial relevo: o cotidiano familiar, a temporalidade social e a competência cultural dos sujeitos. Todos esses lugares não deixam de refletir, de algum modo, a ênfase dada à recepção, vislumbrada como instância privilegiada de investigação da apropriação, do impacto, da ressignificação e das expressões do que é produzido pela mídia.

Stig Hjarvard (2014) sintetiza muito bem as tradições de estudos da comunicação, indicando que entre elas houve as que se preocupavam com os efeitos dos meios junto ao público, valorizando "o que a mídia fazia com as pessoas", bem como as pesquisas que, por outro lado, enfatizavam "o que as pessoas fazem com a mídia". O autor aponta, no entanto, que a teoria da midiatização lançou um terceiro ponto de vista, ao sugerir que:
A cultura e a sociedade estão a tal ponto permeadas pela mídia, que talvez já não seja possível concebê-la como algo separado das instituições culturais e sociais. Nessas circunstâncias, a tarefa que nos incumbe é, mais propriamente, tentar compreender de que forma as instituições sociais e processos culturais mudaram de caráter, função e estrutura em resposta à onipresença dos meios de comunicação" (HJARVARD, 2014, p.15).

Nem todos que lançam mão do termo midiatização compartilham do mesmo sentido para o termo. Há diferentes pesos e medidas no modo como os acadêmicos trabalham a midiatização ou como elaboram teoricamente a questão do suposto poder estruturante da mídia ou da lógica midiática, melhor dizendo. Antes de apresentar autores que lidam diretamente com o conceito, vale retomar Martin Barbero, que revisitou sua abordagem dos anos 1980 e propôs, cerca de 10 anos depois ${ }^{1 \mathrm{~V}}$, um novo olhar em relação às ideias de mediação inicialmente pensadas: em vez de priorizar aquilo que ele chamara de mediações da cultura, ele passou a creditar às mediações midiáticas um lugar de maior relevo no interior da própria cultura, uma vez que estas vinham se mostrando cada vez mais imbricadas com outras esferas culturais, como, por exemplo, a política. "Mais do que substituí-la [a política], a mediação televisiva ou radiofônica passou a constituir, a fazer parte da trama dos discursos e da própria ação política" (MARTIN-BARBERO, 2006, p. 14). Conforme Gislene Silva, Martin-Barbero, "migrou das mediações culturais da comunicação para as mediações comunicativas da cultura" (SILVA, 2012, p.110).

No bojo das abordagens teóricas em Comunicação seguindo a tendência de novas posturas sobre a questão 
dos meios e dos modos como eles se integram à realidade sociocultural do século $X X I$, vem crescendo o número de pesquisadores que procuram afirmar que as mídias já não podem ser mais vistas como meros instrumentos dos processos de comunicação e sim como uma "realidade mais complexa em torno da qual se constituiria uma nova ambiência, novas formas de vida, e interações sociais atravessadas por novas modalidades do 'trabalho de sentido'" (FAUSTO NETO, p. 2008, p. 92). Nesse sentido, até ao próprio conceito de medium, anteriormente tão enraizado em sua etimologia e tão associado à ideia de instrumento de comunicação, são incorporados esforços de ressignificação. Sodré defende que, em face do atual cenário midiático, medium não se restringe à ideia de canal ou veículo, e sim é visto como "canalização (...) e ambiência estruturadas com códigos próprios" (SODRÉ, 2002, p.20). Para ele, o termo pode ser aplicado tanto às mídias de massa quanto às novas tecnologias digitais em rede, porque, conforme explica, "medium é o fluxo comunicacional, acoplado a um dispositivo técnico (...) e socialmente produzido pelo mercado capitalista, em tal extensão que o código produtivo pode tornar-se 'ambiência' existencial” (SODRÉ, 2002, p.20).

Como se percebe pelas citações anteriores, "ambiência" é uma terminologia da qual alguns autores lançam mão para explicar o tipo de mudança epistemológica - e, sob a ótica dos desenvolvedores e defensores do conceito da midiatização, inclusive empiricamente verificável - associada às transformações que têm relação com as comunicações deste período em que virtualidade e conexão em rede estruturam os fluxos de informação nos mais variados espaços do globo. Ambiência remete à ambiente, que abrange toda a existência e, no limite refere-se à sustentação da vida. Sodré (2002) adota a terminologia "quarto bios" para denominar essa nova vivência do mundo da experiência, que é a da sociedade midiatizada, a qual se caracteriza pela presença de mediações tecno-mercadológicas que levam a relações humanas cada vez mais virtualizadas e perpassadas pelo viés do consumo. Nessa concepção, o bios midiático consiste numa espécie de clave virtual aplicada à vida cotidiana, à existência real e histórica do indivíduo. Esse âmbito existencial do homem contemporâneo é comparado à condição existencial do principal personagem de $\mathrm{O}$ show de Truman (1998), filme que conta a história de uma pessoa que foi, durante muitos anos, desde bebê, e sem saber, o personagem central de um reality show, tendo crescido numa espécie de bolha, a qual ele pensava ser a totalidade do mundo, mas que era, na verdade, um grande estúdio de televisão especialmente montado para o programa. Esse filme também é citado nas reflexões do holandês Mark Deuze (2009), quando ele avalia a onipresença midiática, julgando que é mais adequado falarmos da vida na mídia do que da vida com a mídia. Na metáfora de Deuze (2009), o universo em que vivemos é o universo midiático; já não é mais possível estar fora dele; ele seria equivalente ao ambiente aquático para os peixes. Assim como a água os envolve, os nutre, é o ambiente em que eles vivem e dali não podem sair, igualmente seria a ambiência midiática na contemporaneidade.

Há, nessas perspectivas, a percepção de que a midiatização implica uma naturalização cada vez maior não só dos dispositivos tecnológicos, mas também da lógica consumista e das formas de sociabilidade que eles ajudam a produzir, de modo que fica cada vez mais difícil conceber as interações humanas de toda sorte - e não só aquelas comunicações profissionalizadas, apa- 
relhadas midiaticamente - fora desse universo. Considerando assim, a noção de midiatização parece apontar para uma dimensão totalizante e inexorável da vida e da cultura ou, no mínimo, sugerir um caminho que ainda está sendo trilhado, um processo histórico sem volta. As versões mais enfáticas acabam soando como fatalistas. Parecem conceber a aniquilação, a substituição (se ainda não completa, em vias de conclusão) de antigos mediadores sociais por instâncias que continuam a manter os mesmos nomes e, aparentemente, as mesmas funções, mas cujas engrenagens axiológicas passaram a ser moldadas pelo teor intrínseco desse admirável (?!) mundo novo.

Sodré (2008) chega a sugerir comparações do bios midiático com Deus`. Sua comparação não é uma afirmação peremptória (muito menos teológica), e sim mais uma frase de efeito (isso foi dito durante uma entrevista em 2008) para ilustrar a grandiosidade do fenômeno comunicacional de que ele trata. Pondera, no entanto, que uma vez considerada veementemente a questão do livre-arbítrio, sabe-se que não há um domínio absoluto sobre o indivíduo, que consegue entrar e sair desse universo, porém, o autor insiste que "nas condições civilizatórias em que vivemos (urbanização intensiva, relações sociomercadológicas), onde há um predomínio do valor da troca capitalista, estamos imersos nessa virtualidade midiática e isso nos dá uma forma de vida vicária, que quer substituir Deus." (SODRÉ, 2008, s.p.) $)^{\mathrm{l} "}$

Sem lançar mão de metáforas religiosas, José Luiz Braga refere-se à midiatização como um "processo interacional de referência" que se sobrepõe aos demais:

Um processo interacional 'de referência', em um determinado âmbi- to, 'dá o tom' aos processos subsumidos - que funcionam ou passam a funcionar segundo suas lógicas. Assim, dentro da lógica da midiatização, os processos sociais de interação mediatizada passam a incluir, a abranger os demais, que não desaparecem mas se ajustam. (BRAGA apud BARROS 2012, p. 80)

Friedrich Krotz (2007) desenvolve reflexões que sustentam a ideia de que a midiatização constitui o que ele chama de "metaprocesso", isto é, um processo orientador de outros processos de interação social. Para ele, a midiatização, assim como a globalização, a industrialização, a "comercialização"VII, a individualização, abarca uma série de desenvolvimentos que pode durar séculos e não está confinada a uma área limitada (por isso, não é meramente um "processo"). Todos os metaprocessos são capazes de afetar a cultura e a sociedade em níveis micro e macro; influenciam a democracia, a política, as formas de vida, as atividades das instituições, as ações das pessoas e assim por diante. Portanto, segundo Krotz, na análise dos metaprocessos é possível coletar dados sobre mudanças na cultura e na sociedade.

Boa parte dos recentes estudos de comunicação têm sido eficientes na análise de traços da cultura na era das tecnologias digitais e da rede, sendo capazes de demonstrar que, de fato, inúmeros aspectos da vida hodierna estão globalmente afetados pelos fluxos da comunicação virtual conectada. Não é difícil perceber que a Internet e os recursos da convergência de mídia trazem novidades para os modos como as pessoas (e instituições) se comunicam, como produzem memórias, constroem identidade, realizam transações econômicas, lidam com os saberes e os processos de aprendizagem, vinculam- 
-se e/ou agem politicamente, como vivenciam a religiosidade etc.

No entanto, é necessário aqui fazer um alerta. Ao se falar em "metaprocesso", vale questionar em que dimensão essa preposição "meta" está sendo compreendida, porque há uma diferença expressiva entre considerar o metaprocesso como algo superior à própria cultura num sentido sobredeterminador da mesma, ou conceber o metaprocesso como processos de grande duração, amplitude e permeabilidade, os quais podem orientar, influenciar manifestações culturais, mas que não podem ser percebidos como megapoderes independentes e desvinculados da cultura, da economia, da política e até das ações intencionais estratégicas de determinados agentes sociais em cada momento histórico. Ora, se o objetivo de um trabalho acadêmico é compreender honestamente uma dada realidade, sem panfletagem ideológica ou sem promover conclusões apressadas ou simplórias, então é forçoso admitir que há uma imbricação complexa entre os fatores que concorrem para se delinear um fenômeno qualquer. Vale inclusive adicionar o fator do imponderável, pois eventualmente até o inusitado, como catástrofes não previstas, tipo terremotos, tsunamis ou coisas do tipo, pode ser capaz de afetar o modus vivendi como um todo. Assim, o termo metaprocesso pode até ser incorporado ao vocabulário de trabalhos sobre aspectos da cultura desde que não se prenda a um determinismo daquele em relação a estes. É bom que não se esqueça que os metaprocessos se compõem de elementos culturais ao mesmo tempo em que ajudam a influenciar a cultura, isto é, eles perpassam a cultura e são perpassados por ela.

Ampliando o mesmo tipo de argumento para a noção de midiatização, é interessante notar que Stig Hjarvard
(2014) também ataca o simplismo de certas abordagens, alertando para o perigo de concepções muito abrangentes e totalizadoras, as quais tendem a dar um lugar de tamanho destaque à midiatização a ponto de colocá-la num patamar de explicação máxima para toda a realidade no mundo contemporâneo:

...consideramos que a compreensão pós-modernista de midiatização [é] ao mesmo tempo simples demais e ambiciosa demais. Simples demais, porque sugere uma única transformação, com a realidade mediada suplantando a realidade experiencial e as distinções tradicionais simplesmente se dissolvendo. O conceito de midiatização proposto neste livro não endossa a ideia de que a realidade mediada reine soberana, tampouco a alegação de que as distinções ontológicas convencionais tenham desmoronado. A midiatização tal como aqui a concebemos, sugere antes uma expansão das oportunidades de interação nos espaços virtuais e uma diferenciação do que as pessoas percebem como real." (HJARVARD, 2014, p.33. grifo no original).

\section{Comunicação, midiatização, religião}

A internet e as tecnologias digitais estão imbricadas num cenário de profundas transformações nos modos como os indivíduos e coletividades estabelecem vínculos (políticos, econômicos, educacionais, afetivos...) no mundo contemporâneo. É quase impossível imaginar um espaço de convivência humana ou uma instância tradicional da cultura em que as novas realidades midiáticas não estejam, de algum modo, agregadas ou, num sentido mais profundo, tendo chegado a ocupar o lugar de eixo central para organizar mensagens e produzir sentido para a vida cotidiana. A política, o direi- 
to, a medicina, o ensino, os esportes, os transportes, o nascimento e a morte, tudo parece ter feito concessões, em maior ou em menor grau, a um ou vários tipos de intervenção (quiçá até mesmo de incorporação) da lógica midiática. As experiências religiosas e espirituais também demonstram não estar imunes às articulações com os novos cenários, e o interesse pelo tema tem se ampliado entre os pesquisadores brasileiros da área de comunicação, tal como demonstra o levantamento de Priscila Vieira (2014). Tal levantamento também pontua que alguns trabalhos usam "midiatização" como palavra-chave.

As pesquisas do brasileiro Valter Avellar (2010; 2014, em parceria com Silveira) descrevem uma vasta e variada gama de vivências da dimensão do sagrado, do religioso, do espiritual nesse contexto das novas tecnologias de comunicação e informação da era da rede. No espaço fluido das conexões digitais, instituições religiosas tradicionais criam seus sites, blogs e/ou perfis em redes sociais; indivíduos trocam mensagens de e-mails de cariz humanístico e espiritual; religiosos se agrupam em comunidades como as do antigo Orkut (rede social que sobreviveu entre 2004 e 2014); jogadores do Second Life (um jogo que simula uma segunda vida no mundo virtual) fazem com que seus personagens, entre tantas outras atividades, frequentem espaços igualmente virtuais de cariz religiosos; fieis acessam sites onde "acendem" velas ou realizam atos virtuais de piedade relacionados com sua crença. Há, inclusive, curiosas formas de "ciberreligião", com o aparecimento de adoradores da máquina e da tecnologia.

Além desses, há vários exemplos que ilustram brechas abertas do universo religioso à lógica da mídia. Mas a discussão sobre religião e mídia que incorpora a noção de midiatização pode carregar a reboque, mesmo que sequer tome consciência disso, toda a problemática conceitual apresentada anteriormente. Assim, primeiramente, ao se estudar as situações em que a comunicação e o universo espiritual, religioso vêm se relacionando, é lícito perguntar em que profundidade a lógica da mídia tem sido capaz de afetar uma fé, uma espiritualidade, algum aspecto da(s) religião(ões). É válido levantar a hipótese de se a religião está mesmo se tornando cada vez mais imbricada axiologicamente com essa lógica; quer dizer, é preciso indagar até que ponto ela permite (mesmo involuntariamente) que seus próprios valores sejam mesclados com os midiáticos, no pior dos casos até substituídos por estes. E ao se fazer isso, é importante sempre apontar de que maneira a lógica da mídia é compreendida na contemporaneidade. Para Sodré (2002), trata-se da midiatização, noção que precisa ser percebida a partir da multiplicação de interações fundamentadas na preponderância da técnica e do mercado.

Seguindo tal linha de raciocínio e sabendo que a religião é um dos mais relevantes traços de uma cultura, são muito produtivas as reflexões acerca da relação entre religião e mídia que partem da investigação de situações em que a mídia influencia práticas e instituições religiosas contemporâneas, que incorporam o uso dos meios (de massa ou digitais) em suas atividades, não apenas do ponto de vista da instrumentalização dos meios, mas permitindo uma invasão de valores técnicos e mercadológicos. Estão nesse caminho, por exemplo, alguns trabalhos que analisam fenômenos de vivência da fé como espetáculo. Outros exemplos frutíferos são as pesquisas de Hjarvard sobre religião, levando em conta o seu olhar sobre a midiatização. Além de investigar os usos que certos grupos religiosos fizeram dos meios, ele também 
se dedicou a analisar práticas midiáticas com traços de religião e/ou espiritualidade (por exemplo, o aumento da cobertura jornalística aos assuntos religiosos, ou o que ele chamou de "reencantamento" dos meios). Em inquéritos realizados em 2005, 2006 e 2009 na Dinamarca, detectou que o contato dos entrevistados com assuntos espirituais era proveniente, em primeiro lugar, de fontes como a família e os amigos, a televisão, os livros não-ficcionais e a internet. Todos esses foram citados antes dos textos sagrados e da frequência a igrejas.

A ampliação do olhar sobre a mídia contemporânea para além da instrumentalização também se verifica junto à própria Igreja católica, que tem se mostrado atenta aos novos ventos da comunicação social. Dois destes papas mais recentes, João Paulo II e Bento XVI, justamente os dois que se destacam por suas trajetórias acadêmicas, manifestaram que o olhar da Igreja para as realidades comunicacionais contemporâneas não se restringe apenas ao intuito pragmático de ampliar a eficiência dos canais de evangelização, mas almeja refletir sobre os modos de vida que se configuram no mundo atual em face das transformações de cunho mais amplo. É o que expressou a carta apostólica "O rápido desenvolvimento", do então Papa João Paulo II, em 2005; é o que se evidenciou no discurso de Bento XVI, em 2011, na Assembleia Geral do Pontifício ConseIho das Comunicações Sociais: "Não se trata somente de exprimir a mensagem evangélica na linguagem atual, mas é preciso ter a coragem de pensar de maneira mais profunda, como aconteceu em outras épocas, a relação entre a fé, a vida da Igreja e as transformações que o homem está vivendo" (BENTO XVI apud SPADARO, 2012, p.9).

Quer dizer: não se trata apenas de investigar os usos que instituições ou grupos religiosos fazem com meios, ou como o público interage com as mensagens religiosas distribuídas pela mídia, ou tampouco observar como as pessoas, religiosas ou não, usam as mídias para se relacionar. As indagações, hipóteses, bem como algumas formulações mais ousadamente propositivas, procuram elucidar como o lugar central que a mídia passou a ocupar nas atuais configurações do mundo social cria (ou ajuda a criar) novos padrões de comportamento, novas demandas, novas posturas em áreas que não se fundamentavam nem se estruturaram com e pela mídia (por exemplo, a política, a educação, o direito e a religião). Mas será que propor indagações nesses termos tem o mesmo peso ou seria a mesma coisa que falar de política midiatizada, educação midiatizada, direito midiatizado, religião midiatizada (no sentido de considerar que há uma reorganização estrutural axiológica desses campos de acordo com a nova lógica midiatizada)? Certamente que não. Neste caso, seria necessário realizar pesquisas cuidadosas, adentrando regiões de bastidores das referidas práticas, realizando observações de prazo relativamente longo e considerando multiplicidades internas a cada campo. Como visto, afirmações científicas de validade e pertinência suficientes para se confirmar a ideia de um metaprocesso não podem tomar por base apenas alguns exemplos ou estudos de caso.

Elaborações hipotéticas e - pior afirmações tidas como dado dirigidas a consolidar a proposta epistemológica da mídia-deus mostrar-se-iam ainda mais problemáticas se dirigidos à noção de fé. Entendendo a fé como um fenômeno que tem um âmbito impossível de se mensurar: o do vínculo estabelecido com o transcendente divino (ainda que essa experiência possa estar sujeita à influência de aspectos culturais e sociológicos, como a religião), e que, por definição, não 
deixa de incorporar a dimensão inexplicável e enraizada no profundo existencial do indivíduo que a experimenta (seguindo Viktor Frankl), seria, enfim, possível, falar de fé midiatizada?

\section{Palavras finais}

Quando observamos a programação de rádio e televisão, os aplicativos para celular, as mensagens religiosas na internet, não é possível ignorar que as igrejas, os grupos religiosos, as modalidades de culto e de pregação adentraram o universo midiático, mas pode ser apressado e extremamente reducionista concluir que toda esfera do sagrado foi midiatizada. Com efeito, se o assunto é religião, o que se põe em xeque é maior do que o lugar de [alguma] instituição mediadora. As questões da fé, da espiritualidade e do âmbito religioso de maneira ampla e complexa abrangem dimensões ontológicas, às quais convidam - quiçá exigem - sob pena de superficialidade, indagações e questionamentos que nem sempre os estudiosos de comunicação estão dispostos a fazer. E ainda que não se discorra sobre os caminhos a que podem levar tais perguntas, essa seara temática evoca, minimamente, uma consciência sobre sua amplitude e as peculiaridades do vínculo, da axiologia, da adesão que transcendem o aspecto social clássico, uma vez que se trata de considerar uma intersubjetividade em que há um Outro que não é o sujeito humano.

O cristianismo, para tomar um exemplo de maior relevância para a cultura ocidental, muito embora tenha se concretizado historicamente como uma instituição eclesial, além de estar marcado historicamente por uniões e separações institucionais, não pode se resumir a isso. Diante da proposta de desenvolver um olhar complexo sobre um objeto de estudo relacionado com religião, é necessário entendê-lo (ou, no mínimo, considerá-lo) como instância que se define pelo que está para além da esfera da interação social, mas que toca ao sagrado, ao mistério, ao contato com o transcendente (esse não é um traço exclusivo do cristianismo, mas de outras propostas religiosas também). Neste caso específico, é mister considerar que, ao longo da história e nos diferentes territórios, o cristianismo se adaptou aos mais variados formatos de organização política, cultural, econômica e "sobreviveu" a eles. Assim, demonstrou ser um modo de vida, uma proposta universal de "bios religioso" cuja permanência não se ancora na variedade de expressões religiosas, mas naquilo que toma como verdade revelada e encarnada.

Em síntese, ao investigarmos religião, é necessário levar em conta sua identidade religiosa em termos da sua afirmação de fé ou noção de verdade, bem como não negligenciar o lugar que o âmbito da espiritualidade ocupa na vida humana, já que lida essencialmente com dimensões supra-humanas, supra-culturais. A fé trata do absoluto e na busca dele não quer prender-se na relatividade da cultura. A religião com suas práticas de devoção e manifestação da fé é claramente um traço da cultura, mas na medida em que dá lugar a vivências com o universo espiritual de formas tão íntimas, tão peculiares, tão claramente desconectadas dos aparatos da cultura que transcendem até mesmo a possibilidade de explicação ou de verbalização por exemplo em êxtases, em fenômenos paranormais etc - fatalmente escapa à lógica da midiatização.

Ocorre que essa dimensão tão pouco palpável não será o foco da preocupação deste artigo e talvez apenas trabalhos sobre mística ou discussões teológicas possam acercar esses as- 
pectos. De qualquer modo, fiz questão de levantar todas essas ponderações neste trabalho para que não se pense que as teorias da midiatização, embora importantíssimas para pensar o cenário contemporâneo, sejam suficientes para destrinchar toda a problemática da religião, da fé, da espiritualidade. A dimensão teórica da cultura e da comunicação não são suficientes para abarcar todos esses âmbitos.

Por fim, em homenagem à vertente das ciências humanas que tanto se preocupa em conhecer as dinâmicas da dialética social; para os que reconhecem a importância teórica de abarcar as dimensões de luta pela significação, pelos ordenamentos, pelas legitimações; para os que se recusam a compreender os fenômenos sociais como derivados de processos naturais de evolução, concluo com a reflexão a seguir. $O$ processo de midiatização não ocorre sem conflito ou tensão tendo em vista o nível de resistência - consciente ou não - que os agentes de cada campo (político, artístico, esportivo, educacional, religioso etc) apresentam na incorporação da chamada "lógica da mídia". Quando os valores internos (do campo social ou do indivíduo) se mostram contrários aos da midiatização, esforços se levantam para que papeis sociais, lugares de fala - no caso dos grupos - e uma condição ontológica - no caso do ser humano - não se esfacelem frente à nova ordem da experiência do quarto bios.

\section{Bibliografia}

AVELLAR, Valter Luis de. Internet e espiritualidade: o despertar através das mensagens de e-mail. Rio de Janeiro: Calebán, 2010.

ARAÚJO, Carlos Alberto. A pesquisa norte-americana. In: HOHLFELDT, Antonio; MARTINO, L. C.; FRANÇA, Vera Veiga. Teorias da comunicação: conceitos, escolas e tendências. Petrópolis: Vozes, 2001.

BARROS, Laan Mendes. Recepção, mediação e midiatização: conexões entre teorias europeias e latinoamericanas. In: MATTOS, MA.; JANOTTI JUNIOR, J.; JACKS, N. (orgs.). Mediação \& midiatização [online]. Salvador: EDUFBA, 2012, pp. 79-105. Disponível em http://books.scielo. org/id/k64dr/pdf/mattos-9788523212056-05.pdf, acesso em 30 dez. 2016.

COMTE-SPONVILLE, André. O espírito do ateísmo: introdução a uma espiritualidade sem Deus. São Paulo: WMF Martins Fontes, 2007.

DEUZE, Mark. Media life. Cambridge (UK): Polity Press, 2009.

FAUSTO NETO, Antônio. Fragmentos de uma «analítica» da midiatização. Matrizes. São Paulo, v. 8, n. 2., p. 89-105, 2008. Disponível em $<$ http://www.revistas.usp.br/matrizes/article/ view/38194/40938>, acesso em: 17 abr. 2017

FRANÇA, Vera Veiga. O objeto da comunicação/ a comunicação como objeto. In: HOHLFELDT, Antonio. MARTINO, L. C. FRANÇA, Vera Veiga. Teorias da comunicação: conceitos, escolas e tendências. Petrópolis, RJ: Vozes, 2001.

FRANKL, Viktor E. A presença ignorada de Deus. 10 Ed. São Leopoldo, RS: Sinodal; Petrópolis, RJ: Vozes, 2007.

GEERTZ, Clifford. A interpretação das culturas. Rio de Janeiro: Zahar, 1978

HJARVARD, Stig. A midiatização da cultura e da sociedade. São Leopoldo, RS: Unisinos, 2014.

KROTZ, Friedrich. The Metaprocess "Mediatization" as a conceptual Frame. Global Media and Communication. n. 3. p. 256-260, 2007. Disponível em <https://www.academia.edu/12136535/ The_meta-process_of_mediatization_as_a_ conceptual_ frame?auto=download $>$, acesso em: 30 abr. 2017. 
MARTIN-BARBERO, Jésus. Dos meios às mediações: comunicação, cultura e hegemonia. Rio de Janeiro: Ed. UFRJ, 2003.

SILVA, Gislene. Pode o conceito reformulado de bios midiático conciliar mediações e midiatização? In: MATTOS, Maria Ângela; JANOTTI JR., Jeder; JACKS, Nilda (orgs.). Mediação \& midiatização. Salvador: EDUFBA; Brasília: Compós, 2012. p. 107-122.

SILVEIRA, Emerson Sena da; AVELLAR, Valter. Espiritualidade e sagrado no mundo cibernético. São Paulo: Loyola, Unicap, 2014.

SODRÉ, Muniz. Antropológica do espelho: uma teoria da comunicação linear e em rede. Petrópolis, RJ: Vozes, 2002.

SPADARO, Antonio. Ciberteologia: pensar o cristianismo nos tempos da rede. São Paulo: Paulinas, 2012.

VIEIRA, Priscila. Comunicação, modernidade e religião: relações culturais na história e produção do Centro Audio Visual Evangélico CAVE. (Doutorado em Comunicação e Cultura). Universidade Federal do Rio de Janeiro, 359 f., 2014

\section{Recebido em 24/05/2017 Aprovado em 04/09/2017}

Freud e, em período posterior à sua libertação com o fim da guerra, voltou a desenvolver suas teorias sobre inconsciente, mantendo o diálogo com a psicanálise freudiana. Suas reflexões sobre a existência humana procuram dar conta de um lugar do espiritual e do transcendente, inclusive abarcando essas dimensões no inconsciente, procurando mostrar que o agir humano não resume-se ao impulsivo.

IV Prefácio à $5^{a}$ edição de língua espanhola do livro "Dos meios às mediações". Texto de 1998.

V Em entrevista à Revista Unisinos (edição 289, de abril de 2009), a entrevistadora Graziella Wolfart dirige a seguinte pergunta a Sodré: "O senhor afirma que "antes da midiatização da sociedade só Deus tinha o poder imediato, global e instantâneo". Acredita que a mídia tenha tanta força assim, com capacidade para mudar profundamente a vida das pessoas e o rumo da sociedade? As respostas que seguem não retomam explicitamente a menção ao divino, mas limitam-se a refletir sobre a questão dos fenômenos da mídia na era das redes e do digital.

VI http://revistapesquisa.fapesp.br/2008/12/01/muniz-sodre/

VII No sentido adotado explicitamente por Krotz (2007), comercialização refere-se ao que ele chama de crescente importância da economia, o que para ele também constitui um metaprocesso de suma importância no mundo capitalista.
I Fernanda Lima Lopes. Doutora e mestre em Comunicação e Cultura pela Universidade Federal do Rio de Janeiro. Pesquisadora de pós-doutorado na UFRJ. Contato: ferlimalopes@gmail.com

II O conceito de religião aqui aplicado percebe a existência de espiritualidade em certos rituais e crenças, mas não considera algumas manifestações como religiões propriamente ditas. Práticas como o budismo, entre outras, consideradas como filosofia, portanto, não se enquadram na definição aqui adotada.

III Antes de ter sido enviado para o campo de concentração em Auchwitz, Viktor Frankl (1905 - 1997) foi médico e psicólogo na Áustria, correspondeu-se com 